\title{
The Analysis of Postal Express Customer Satisfaction In Shanxi Province
}

\author{
Li xin \\ Zhengzhou University of Industrial Technology,Zhengzhou451150, China \\ 996195251@qq.com
}

Keywords: SEM; customer satisfaction; Postal Express in Shaanxi Province

Abstract:In the period of China's express delivery market rapid expansion, the postal express business has declined in Shaanxi Province. Improving customer satisfaction has become the important tool to maintain and increase market. after analyzing postal express logistics business situation and competitors in the Shaanxi province, build shaanxi province postal express customer satisfaction (SEM) model. Conducing validity and reliability test, empirically analysis postal express customer satisfaction in Shaanxi Province. According to the empirical results, it show that prices, Timeliness satisfaction,quality of service have significant impact in Shaanxi postal express customer satisfaction.From the three factors put forward suggestions.

\section{Introduction}

With the rapid development of Chinese express industry, the increasingly fierce market competition, the express market has a very broad prospects for development, In the period of rapid expansion about China's express delivery market, Shaanxi province express business volume is on the decline. In Shaanxi Province, the postal delivery letter business totaled 330960000, has been lowered by $40 \%$ as compared with last year In 2014; the cumulative completion of the package business 159910000 , has been lowered by $15.94 \%$ as compared with last year. Shaanxi province postal courier must ensure that there is a long-term purchase of corporate goods consumer groups. Customer satisfaction is the key to the long-term development of enterprises.

Customer satisfaction theory research mainly concentrated in the following two aspects: the concept of customer satisfaction and customer satisfaction model. The concept of customer satisfaction basically can be summarized as two main point of view: a point of view is to customer satisfaction as a process; And another is the customer satisfaction as the result of a consumer activity.

DonaldJ.Bowersox, DavidJ.Closs and MB.Cooper put forward that if the customer service level of logistics providers expect to be met,customers will be satisfied ${ }^{[1]}$. In the process of forming the model of customer satisfaction: the scholars from different countries develop some customer satisfaction models, the most famous model is derived from the Swedish SCSB customer satisfaction model and the model of American customer satisfaction ACSI ${ }^{[2]}$. Liu Xinyan based on the SCSB model and ACSI model analysis, remove customer the factor of complaint, and Change perceived value to perceived price ${ }^{[3]}$. Tang Sheng and Meng Xianzhong (2011) according to the analysis of customer satisfaction index, build customer satisfaction index model using RobustPLS method $^{[4]}$. Chen Fangjian (2012)summarizes the domestic and foreign customer satisfaction theory 
and indicators, mainly divided customer satisfaction index into service prices, corporate image, job quality and other ${ }^{[5]}$. Gao Junguang, Lin Ying and Liu Huili (2013) fusion PRCA model thought, divided the evaluation index system of customer satisfaction into three factors: basic factors, incentive factors and performance factors ${ }^{[6]}$.

Based on the above research results, the multiple regression method to measure customer satisfaction has become the most widely used method. In addition, More and more scholars study the third party logistics enterprises, but the view of Shaanxi province postal express customer satisfaction research is not much, in the choice of index factors too narrow, still need to do research on customer satisfaction further.

\section{Analysis of the present situation of postal express delivery in Shaanxi Province}

For a long time, the postal delivery price does not follow the laws of the market, lack of flexible price mechanism. Price strategy also has strict rules,and can not be adjusted according to market dynamics, lack of flexibility to respond to market changes ${ }^{[7]}$.

Postal delivery price is high, because of the price to take the uniform tariff price system, make The short-range express price is excessive. The timeliness of the information processing system is slow, the inquiry system is very weak, the user query often does not show up in the computer。 Postal express transport mainly by rail and civil aviation. Mail transportation lines and operation time are affected by the arrangement of the railway running trips, civil aviation flight. Express time can not be guaranteed; service quality is low, and service awareness needs to be improved.

\section{Customer satisfaction index system and model construction}

Combing and summarizing the literature about customer satisfaction index, reference Chinese CCSI index model, combined with the Shaanxi province postal express the characteristics of its development, put forward with its own characteristics of the satisfaction index system (Tab. 1), and the establishment of model. Data is obtained directly from the survey, through the reliability and validity of the test, the input model to get the impact factor model, as shown in figure 1. the parameter of Fig.1 results in Tab.2, And pass the test at the 5\% significance level through the test. 
Tab.1 Customer satisfaction index system

\begin{tabular}{|c|c|c|c|}
\hline Latent & measurable & Latent variable & measurable variable \\
\hline \multirow{5}{*}{$\begin{array}{c}\text { customer } \\
\text { satisfaction } \eta_{1}\end{array}$} & \multirow{3}{*}{$\begin{array}{l}\text { Overall satisfaction } \\
\text { V1 }\end{array}$} & \multirow{2}{*}{$\begin{array}{l}\text { Corporate image } \\
\eta_{2}\end{array}$} & $\begin{array}{l}\text { brand image V4 } \\
\text { Staff quality V5 }\end{array}$ \\
\hline & & & Service attitude V6 \\
\hline & & price $_{3}$ & $\begin{array}{l}\text { Price rationality } \mathrm{V} 7 \\
\text { high performance-price ratio V8 } \\
\text { Reasonable degree of Weight } \\
\text { and price V9 }\end{array}$ \\
\hline & \multirow{2}{*}{$\begin{array}{l}\text { actual service } \\
\text { satisfaction Compared } \\
\text { with the expectations } \\
\text { V2 } \\
\text { Relative service } \\
\text { satisfaction Compared } \\
\text { with competitors V3 }\end{array}$} & $\begin{array}{c}\text { Timeliness } \\
\text { satisfaction } \eta_{4}\end{array}$ & $\begin{array}{l}\text { Timeliness of arrival V10 } \\
\text { processing speed when delivery } \\
\text { v11 } \\
\text { Internet query tracking v12 }\end{array}$ \\
\hline & & $\begin{array}{c}\text { quality of service } \\
\eta_{5}\end{array}$ & $\begin{array}{l}\text { Convenience of network service } \\
\text { V13 } \\
\text { hotline service satisfaction V14 } \\
\text { Damage protection of goods } \\
\text { V15 } \\
\text { Goods information security V16 } \\
\text { Delivery accuracy V17 }\end{array}$ \\
\hline
\end{tabular}

Tab.2 Key influencing factors of customer satisfaction

$\eta_{1}$

\begin{tabular}{c|c|c|c}
\hline$\eta_{2}$ & $\eta_{3}$ & $\eta_{4}$ & $\eta_{5}$ \\
\hline 0.168 & 0.206 & 0.292 & 0.271 \\
\hline
\end{tabular}




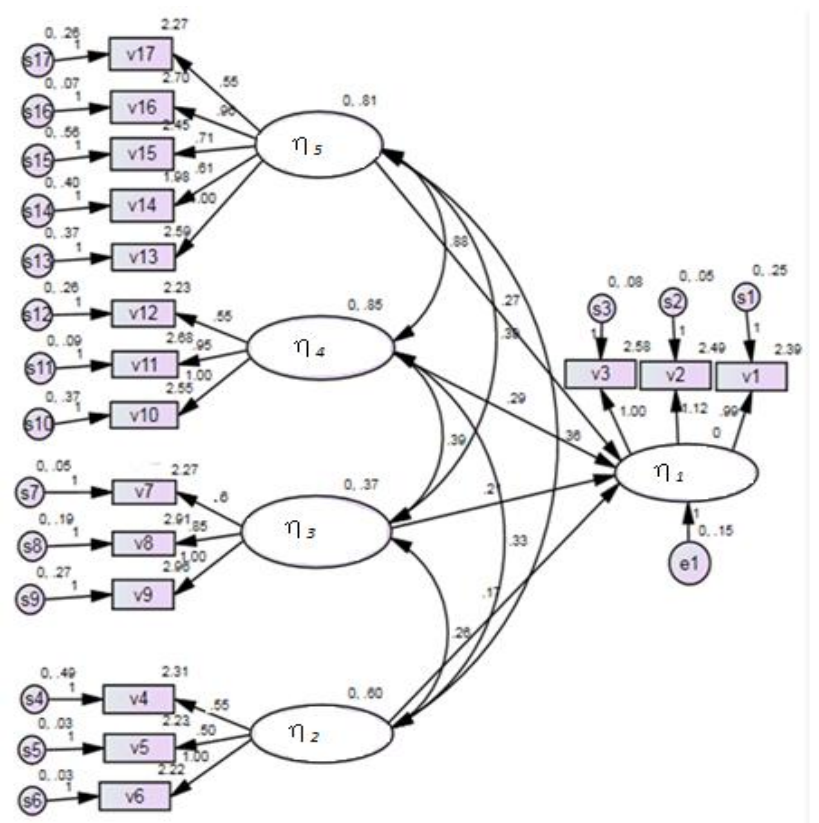

Fig. 1 customer satisfaction model of Shaanxi province postal service express delivery

Specific criteria to determine whether the latent variables are related from the correlation coefficient: the absolute value of the correlation coefficient is less 0.2 , then factors are weak correlation. The absolute value of the correlation coefficient is greater than 0.2 , less than 0.5 , then the two factors are strong correlation. The absolute value of the correlation coefficient is greater than 0.5 , and the two factors are strongly correlated.Therefore, the service price, timeliness and service quality have significant influence on the customer satisfaction of Shaanxi postal express service.

\section{conclusion}

To improve the customer satisfaction of Shaanxi province postal express delivery from three aspects of service price, timeliness satisfaction and service quality: change Uniform price to different Price, and implement the regional independent price; break the old management system, optimize and adjust the reasonable distribution line, improve the distribution speed; take direct postal outlets and joined the agency of combination,and construct convenience and service network. Using two-dimensional code scanning technology, the identity of valid documents and two-dimensional code information is consistent to ensure information security.

\section{References:}

[1] D.J.Bowersox, D.J.Closs and M.B.Cooper. Supply Chain Logtistics Management[J].China Machine Press,2007(9),51-54.

[2] Wang Jing,Li Jinfei.Customer satisfaction evaluation of third party logistics service[J]. Industrial Engineering,2006(5):91-94.

[3] Liu Xinyan,Liu Yan. Construction of a new customer satisfaction index model analysis of SCSB, ACSI, ECSI [J]. Nankai business review,2003(5):52-56.

[4] Tang Sheng,Meng Xianzhong.Robust PLS algorithm the customer satisfaction index of industrial engineering and management based on [J].Industrial Engineering and 
management.2011(16):81-84.

[5] Chen Fangjian. Research on customer satisfaction evaluation standard of logistics enterprises [J]. logistics technology.2012(10):17-20.

[6] Gao Junguang, Lin Ying, Liu Weili. Empirical Study on customer satisfaction evaluation of commercial banks based on PRCA model [J].financial theory and Practice.2013,(03): 60-64.

[7] Feng Yanfang. Influencing factors and evaluation index system of logistics service customer satisfaction [J]. logistics technology,2014.1(33):34-36. 